\title{
Transobturator suburethral tapes in the management of urinary incontinence: success, safety and impact on sexual life
}

\author{
Mohamed Abdel-fattah • Ian Ramsay • \\ Stewart Pringle $\cdot$ Stein Bjornsson • Chris Hardwick • \\ John Tierney $\cdot$ Hassan Ali $\cdot$ David Young
}

Received: 11 November 2006 / Accepted: 14 June 2007 / Published online: 19 July 2007

(C) Springer-Verlag 2007

\begin{abstract}
This study aims to assess transobturator tensionfree vaginal tapes (TOT) in regard to subjective cure rates, patient satisfaction, long-term morbidity and impact on patients' sexual life. It also aims to compare the safety profile of two TOTs: Obtape (outside-in technique) vs. TVT-O (inside-out technique). This is a retrospective study of all patients who had a TOT procedure for the management of urodynamic stress incontinence (USI) in a tertiary referral centre between July 2002 and January 2005. All patients identified from theatre records were sent an anonymous validated assessment questionnaire including the urinary domain of Birmingham Bowel and Urinary Symptoms Questionnaire, International Consultation on Incontinence Questionnaire Short Form (ICIQ-SF), Sexual Impact Questionnaire and a visual analogue scale (VAS) to assess patients' satisfaction. Case notes were examined to ascertain preoperative urodynamic diagnosis and perioperative complications. Two hundred and seventy-six women were identified from theatre records: 94 patients underwent TVT-O and 182 underwent Obtape . Mean age was 49 (range 34-78) years, and mean parity was two (range:
\end{abstract}

Both techniques of TOT are safe in the treatment of USI and are associated with high subjective success rate and improvement or on change in patients' sexual life.

M. Abdel-fattah $(\bowtie) \cdot$ I. Ramsay $\cdot$ S. Pringle $\cdot$ S. Bjornsson

C. Hardwick $\cdot$ J. Tierney $\cdot$ H. Ali

Urogynaecology Unit, Greater Glasgow Health Board,

1345, Govan Road,

Glasgow G51 4TF, UK

e-mail: Mohamed.abdelfattah@sgh.scot.nhs.uk

D. Young

Glasgow University,

Glasgow, UK
0-6). There was no difference between groups in regard to body mass index, urodynamic diagnosis and previous incontinence surgery. Intraoperative complications included bladder injury $0.4 \%$, urethral injury $0.7 \%$, lateral vaginal tears $4.3 \%$ and blood loss $>200 \mathrm{ml}$ in $5.4 \%$. There was no statistically significant difference in intraoperative $(p=0.2)$ and early postoperative $(p=0.65)$ complications between groups. Late postoperative complications were mainly related to the tape material and included de novo urgency $(6.9 \%)$, vaginal erosions $(5.1 \%)$ and ischiorectal abscess (1.1\%). A significantly higher rate of late postoperative complications occurred in the Obtape group $(p=0.047)$. Median follow-up was $28 \pm$ standard deviation(SD) 4.8 (range 10-40) months. Subjective success rate, defined as absent or occasional episodes of incontinence according to the ICIQ-SF was $86 \%$ in the USI group compared with $52.4 \%$ in the mixed incontinence group $(p<0.001)$. Following the operation, there was no significant change in patients' sexual life as regards frequency of intercourse and pleasure and/or pain during penetration $(p=1.000)$, whereas there was significant decrease in coital incontinence $(p<$ $0.0001)$. TOT is a relatively safe procedure in the treatment of USI and is associated with a high subjective success rate with a median follow-up of 28 months. Coital incontinence is likely to be cured, and the vast majority of women described an improvement or no change in their sexual life following the TOT procedure. There was no significant difference in the complication rates between the outside-in vs. the inside-out techniques; however, significantly more "tape-related complications" occurred in the Obtape group.

Keywords Transobturator tension-free vaginal tape . Urodynamic stress incontinence $\cdot$ Female sexual dysfunction 


\section{Introduction}

The year 2006 marked the tenth anniversary of the description by Ulmsten et al. [1] of the tension-free vaginal tape operation (TVT) for surgical treatment of urodynamic stress incontinence (USI). The mechanism of action of TVT is best explained by the "integral theory" for continence [2]. Over the last decade, TVT has become the most popular treatment for USI, with a massive literature to support its effectiveness and detail its complications [3, 4]. Transobturator tension-free vaginal tape (TOT) was first described in 2001 by Delorme [5] as an alternative treatment of USI that would keep the principle of a minimally invasive procedure supporting the midurethra whilst avoiding the blind entry to the retropubic space and therefore minimise the risk of injury to internal organs. The TOT is inserted tension free in a horizontal plane underneath the midurethra between the two-obturator foramina. The tape is then tunneled percutaneously around the inferior pubic ramus and guided by the surgeon's finger into the suburethral vaginal incision, i.e. "outside-in technique". In 2003, De Leval [6] described a further modification, i.e. "inside-out technique", which allows insertion of the TOT from the vagina into the obturator space using a "winged guide". De Leval reported less intraoperative complications with his new technique. Several reports have been published on the short- and medium-term effectiveness of the procedure [7-10] as well as its relatively lower perioperative morbidity when compared with TVT [1113]. However most of these studies have limited follow-up periods, and none of them have assessed the impact of TOT on patients' sexual life.

This study aims to assess the TOT procedure in general in regard to subjective cure rates, patient satisfaction and impact on patients' sexual life. It also compares the safety profile of the two TOTs used: Obtape (outside-in technique) vs. TVT-O (inside-out technique).

\section{Patients and methods}

This is a retrospective study of all patients who had a TOT procedure for the management of USI in a tertiary referral centre in the south-west of Scotland between July 2002 and January 2005. In our department, the transobturator approach for TVT was introduced in July 2002 and has been the first-choice treatment for USI since July 2003. This study was approved by the local ethics committee and was conducted by an independent clinician. Patients were identified from theatre records, and case notes were examined for patient demography to ascertain urodynamics diagnosis and identify the operative and immediate postoperative complications. All patients were sent a study pack including letter of invitation, consent form and an anonymous questionnaire that included the urinary domain of the Birmingham Bowel and Urinary Symptoms Questionnaire (BBUSQ-22) [14], International Consultation on Incontinence Questionnaire Short Form (ICIQ-SF) [15] and a visual analogue scale (VAS) to assess patient satisfaction. The Sexual Impact Questionnaire [16] included details on pre- and postoperative sexual function of patients and their partners. Extra questions were added to assess preoperative details such as urgency and other questions to assess longterm morbidity such as intermittent self-catheterization. The questionnaires were sent in October 2005, giving a minimum 10-month and up to 40-month follow-up [median 28 months \pm standard deviation (SD) 4.8 months]. Those who did not reply were recontacted twice at 6-week intervals by phone and/or mail.

Two types of tapes had been used: Obtape (MentorPorges) and TVT-O (Gynaecare), utilising the outside-in and the inside-out techniques, respectively, with the choice of tape being primarily decided upon by surgeon preference. Preoperative assessment included detailed history, comprehensive pelvic examination, and urodynamic assessment. Patients with USI and patients with mixed incontinence [USI plus detrusor overactivity (DO)] yet with predominantly USI symptoms were offered surgical treatment after failed/declined supervised pelvic-floor muscletraining programme. Both procedures were performed as originally described $[5,6]$. In our protocol, all patients received intraoperative broad-spectrum antibiotics. Postoperative indwelling catheter was reserved for those who underwent regional anaesthesia. Satisfactory voiding was defined as postvoiding residual urine volume $<100 \mathrm{ml}$ on two occasions where the voided volume was more than $200 \mathrm{ml}$. The residual urine was assessed by ultrasound scan.

Descriptive statistics were produced, and between-group comparisons of categorical responses were done using Fischer exact test and chi-squared tests, as appropriate. McNemar's test was used for paired comparisons. All analyses were performed using Minitab (version 14), with a significance level of $5 \%$.

\section{Results}

\section{Patient characteristics}

Two hundred and seventy-nine patients underwent TOT within the study period July 2002-January 2005. Two patients with multiple sclerosis and one with missing notes were excluded, leaving 276 cases for analysis. Mean age was 49 (range 34 78 ) years, and mean parity was two (range $0-6$ ). Sixty patients were having secondary anti-incontinence procedures: 31 following colposuspension, 24 following TVT and five 
following other procedures. Ninety-four patients underwent TVT-O, and 182 patients had an Obtape procedure. There was no difference between groups in regard to body mass index, urodynamic diagnosis and previous incontinence surgery; however, more patients in the Obtape group were menopausal and/or had previous hysterectomy (Table 1).

\section{Transobturator tape complications}

We classified complications into intraoperative, early postoperative (occurred within 2 weeks of the operation) and late postoperative (occurred after 2 week of surgery). There was no significant difference between the Obtape and TVT-O groups in regard to the intraoperative $\left(X^{2}=1.723, p=\right.$ $0.2)$ and early postoperative complications $\left(X^{2}=0.21 p=\right.$ $0.65)$. However, there was a significantly higher rate of late-onset postoperative complications in the Obtape group compared with the TVT-O group $(p=0.047)($ Table 2$)$.

We have previously reported on various complications associated with TOT [17-19], and we include here a brief mention of the complications encountered in this cohort of patients and their management. Three cases of lower urinary tract injuries occurred in this cohort, all of which were in the Obtape group. The two cases of urethral injuries occurred in secondary procedures [17], where it was noted that the anterior vaginal wall was extremely thin and fibrosed. The injuries occurred at the time of suburethral incision, they were then closed in two layers and the procedure was completed with the tape inserted and adjusted tension free. A urethral catheter was left in situ for 10 days. In the single case of bladder injury [17], the tape perforated the bladder at the time of the right arm insertion. This was diagnosed with persistent mild postoperative haematuria and irritative bladder symptoms, and cystoscopic resection of the TOT was performed a few weeks later. No patient required a blood transfusion, and there were no cases of symptomatic pelvic haematoma. One case of complete retention occurred in the Obtape group and was managed with surgical release of the tape. Vaginal tape erosion occurred in 14 cases $(5 \%), 12$ of which were in the Obtape group [18]; all presented 145 weeks postoperatively, with abnormal vaginal discharge and/or vaginal bleeding, whereas one patient was asymptomatic. One patient was managed with vaginal refashioning and six with surgical excision of the eroded part of the tape under antibiotic cover. However complete tape removal was necessary in the other seven patients with local signs of infection. None of the patients in this study had urethral erosion.

Three patients who presented with purulent vaginal discharge and groin pain were found to have unilateral ischiorectal fossa abscess on computed tomography (CT) scan. These cases required complete removal of the tape and surgical evacuation of the abscess by the surgical team. One case of perineal cellulites was diagnosed on the fifth postoperative day [19] and was successfully managed with intravenous antibiotics.

\section{Success rates}

Out of the 276 questionnaires sent, 242 women replied, for a response rate of $87 \%$. This included $158(65.3 \%)$ patients with USI and $84(34.7 \%)$ with mixed incontinence. The median follow-up period was 28 (range 10-40) months. The patients were asked to assess the improvement in their stress urinary incontinence (UI) following the operation (Table 3). Using definitions of "cured" or "significantly improved", patient-assessed success rate was significantly higher in the group of women with USI (84.8\%) compared with $50.1 \%$ in women with mixed incontinence $\left(X^{2}=33.5\right.$, $p<0.001)$. When subjective success rate was defined as absence or occasional episodes of incontinence according to ICIQ-SF, the success rate in the USI group was $86 \%$ compared with $52.4 \%$ in the mixed incontinence group (Table 4) $\left(X^{2}=32.7, p<0.001\right)$.

One hunded and forty-three (59\%) of the responding patients described preoperative urgency, which was cured or significantly improved in $17.3 \%$, whereas $14.4 \%$ reported slight improvement and $60 \%$ described no change. The

Table 1 Patient characteristics

\begin{tabular}{|c|c|c|c|c|}
\hline Characteristics & $\begin{array}{l}\text { Total } \\
\mathrm{n}=276(\%)\end{array}$ & $\begin{array}{l}\text { Obtape } \\
\mathrm{n}=182(\%)\end{array}$ & $\begin{array}{l}\text { TVT-O } \\
\mathrm{n}=94(\%)\end{array}$ & Chi-square test $\left(\mathrm{x}^{2}\right)$ \\
\hline Previous incontinence surgery & $60(21.7 \%)$ & $38(21 \%)$ & $22(23 \%)$ & $p=0.23$ \\
\hline Previous hysterectomy & $144(52.2 \%)$ & $92(50 \%)$ & $32(34 \%)$ & $p<0.01^{*}$ \\
\hline USI & $175(63.4 \%)$ & $111(60 \%)$ & $64(68 \%)$ & $p=0.44$ \\
\hline Mixed incontinence (mixed USI \& DO) & $101(36.6 \%)$ & $71(39 \%)$ & $30(32 \%)$ & $p=0.58$ \\
\hline $\mathrm{BMI}>30$ & $147(53.2 \%)$ & $96(53 \%)$ & $51(54 \%)$ & $p=0.06$ \\
\hline Menopausal & $162(58.6 \%)$ & $117(64 \%)$ & $45(48 \%)$ & $p<0.01^{*}$ \\
\hline HRT & $62(22.5 \%)$ & $37(20 \%)$ & $25(27 \%)$ & $p=0.64$ \\
\hline
\end{tabular}

USI urodynamic stress incontinence, DO detrusor overactivity, BMI body mass index, HRT hormone replacement therapy

* Statistically significant difference 
Table 2 Complications

\begin{tabular}{|c|c|c|c|c|}
\hline & $\begin{array}{l}\text { Total TOTs } \\
n=276(\%)\end{array}$ & $\begin{array}{l}\text { Obtape } \\
n=182(\%)\end{array}$ & $\begin{array}{l}\text { TVT-O } \\
n=94(\%)\end{array}$ & Fischer exact test \\
\hline \multicolumn{5}{|l|}{ Intraoperative } \\
\hline Bladder injury & $1(0.4 \%)$ & $1(0.6 \%)$ & 0 & $p=1$ \\
\hline Urethral injury & $2(0.7 \%)$ & $2(1.1 \%)$ & 0 & $p=0.55$ \\
\hline Blood loss $>200 \mathrm{ml}$ & $15(5.4 \%)$ & $9(5 \%)$ & $6(6.4 \%)$ & $p=0.59$ \\
\hline Lateral vaginal wall tears & $12(4.3 \%)$ & $11(6 \%)$ & $1(1 \%)$ & $\begin{array}{l}p=0.06 \\
\text { Chi-square }=1.723\end{array}$ \\
\hline Total & $30(10.8 \%)$ & 23 & 7 & $p=0.2$ \\
\hline \multicolumn{5}{|l|}{ Early postoperative } \\
\hline Perineal cellulites & $1(0.4 \%)$ & $1(0.6 \%)$ & 0 & $p=1$ \\
\hline Urinary tract infection & $14(5.1 \%)$ & $8(4.4 \%)$ & $6(6.4 \%)$ & $p=0.56$ \\
\hline Complete urinary retention & $1(0.4 \%)$ & $1(0.6 \%)$ & 0 & $p=1$ \\
\hline Voiding difficulties: $24 \mathrm{~h}-1$ week & $15(5.4 \%)$ & $9(5 \%)$ & $6(6.4 \%)$ & $p=0.59$ \\
\hline Voiding difficulties: more than 1 week & $7(2.5 \%)$ & $5(2.7 \%)$ & $2(2.1 \%)$ & $p=1$ \\
\hline Surgical tape release & $4(1.5 \%)$ & $3(1.6 \%)$ & $1(1 \%)$ & $p=1$ \\
\hline CISC & $3(1.1 \%)$ & $2(1.1 \%)$ & $1(1 \%)$ & $p=1$ \\
\hline Pain necessitating readmission & 1 & 0 & $1(1 \%)$ & $\begin{array}{l}p=1 \\
\text { Chi-square }=0.21\end{array}$ \\
\hline Total & $46(16.7 \%)$ & 29 & 17 & $p=0.65$ \\
\hline \multicolumn{5}{|l|}{ Late postoperative } \\
\hline Vaginal mesh erosion & $14(5.1 \%)$ & $12(6.6 \%)$ & $2(2.1 \%)$ & $p=0.15$ \\
\hline De novo urge symptoms & $19(6.9 \%)$ & $14(7.7 \%)$ & $5(5.3 \%)$ & $p=0.6$ \\
\hline Ischiorectal abscess & $3(1.1 \%)$ & $3(1.6 \%)$ & 0 & $\begin{array}{l}p=0.55 \\
\text { Chi-square }=3.94\end{array}$ \\
\hline Total & $36(13.1 \%)$ & 29 & 7 & $p<0.047^{*}$ \\
\hline
\end{tabular}

TOT transobturator tension-free vaginal tape, CISC clean intermittent self-catheterization

$P$ is significant at 0.05

* Statistically significant difference

minority of patients $(8.3 \%)$ reported worsening of their preoperative urgency. When asked to assess their satisfaction with the TOT procedure on a VAS, $74 \%$ scored $80 \%$ or more.

Impact on sexual life

Two hundred and two women completed the sexual impact section of the questionnaire, giving a response rate of $73.7 \%$; 142 women $(70.3 \%)$ were sexually active preoperatively. Sixty women were sexually inactive for a variety of reasons: no partner $(n=30)$, partner health problems $(n=$ $14)$, patient health problems $(n=4)$ and combination of reasons $(n=12)$. After the operation, $134(66.34 \%)$ women were sexually active, including four women $(2 \%)$ who were previously not sexually active yet no reason for the change was given. Twelve women $(6 \%)$ became sexually inactive following the operation: six no longer had partners, three had partner-related problems and three had other medical problems. One hunderd and thirty women were sexually active before and after the operation, and they formed the platform for the analysis. McNemar's test was used to compare the differences (Table 5). Following the operation, there was no significant change in sexual life in regard to frequency of intercourse and pleasure and/or pain during penetration $(p=1.000)$, whereas there was significant improvement in coital incontinence $(\mathrm{CI})(p<0.0001)$.
Table 3 Patient-assessed success rate

\footnotetext{
${ }^{a}$ Successful outcome

${ }^{\mathrm{b}}$ Mixed incontinence [urodynamic stress incontinence (USI) plus detrusor overactivity]
}

\begin{tabular}{llll}
\hline $\begin{array}{l}\text { Patient-assessed success rate of stress } \\
\text { incontinence }\end{array}$ & Total & USI & $\begin{array}{l}\text { Mixed } \\
\text { incontinence } \\
n=84(34.7 \%)\end{array}$ \\
\hline $\begin{array}{lll}\text { Cured }(95-100 \% \text { improvement) } \\
\text { Significant improved }(80-95 \%)^{\mathrm{a}}\end{array}$ & $107(44 \%)$ & $97(61.4 \%)$ & $10(12 \%)$ \\
Some Improvement $(50-79 \%)$ & $69(28 \%)$ & $37(23.4 \%)$ & $32(38.1 \%)$ \\
No improvement $(<50 \%)$ & $24(9.9 \%)$ & $12(7.6 \%)$ & $12(14.3 \%)$ \\
Worse & $18(7.4 \%)$ & $10(6.3 \%)$ & $8(9.5 \%)$ \\
& $24(9.9 \%)$ & $2(1.3 \%)$ & $22(26.1 \%)$ \\
\hline
\end{tabular}


Table 4 Subjective success rates according to International Consultation on Incontinence Questionnaire Short Form

\begin{tabular}{llll}
\hline Episodes of incontinence during last 4 weeks & $\begin{array}{l}\text { Total } \\
n=242(\%)\end{array}$ & $\begin{array}{l}\text { USI } \\
n=158(65.3 \%)\end{array}$ & $\begin{array}{l}\text { Mixed incontinence } \\
n=84(34.7 \%)\end{array}$ \\
\hline Never $^{\mathrm{a}}$ & $119(49.2 \%)$ & $93(58.9 \%)$ & $26(31 \%)$ \\
Once or less/week $^{\mathrm{a}}$ & $61(25.2 \%)$ & $43(27.1 \%)$ & $18(21.4 \%)$ \\
$2-3$ times/week & $29(12 \%)$ & $14(8.9 \%)$ & $15(17.9 \%)$ \\
Once/day & $15(6.2 \%)$ & $4(2.5 \%)$ & $11(13.1 \%)$ \\
Several times/day & $18(7.4 \%)$ & $4(2.5 \%)$ & $14(16.7 \%)$ \\
All the time & $2(0.8 \%)$ & 0 & $2(2.4 \%)$ \\
\hline
\end{tabular}

a Successful outcome

experience performed the surgical procedures: a subspecialist urogynaecologist, three urogynaecologists, five general gynaecologists, a subspecialist registrar and a number of specialist registrars. The results therefore reflect the success and safety profile of these procedures throughout the learning curve of most surgeons, and we therefore believe that the results are generalisable. It is important to note that a few complications, such as lateral vaginal wall tears, were mainly encountered in the beginning of the learning curve (performed $<20$ procedures); however, they were also related to other risk factors, such as thin vaginal walls secondary to previous surgery and/or postmenopausal status.

The subjective success rate of TOT in this study was $76 \%$ with median follow-up of 28 month. We used two tools to assess the subjective outcome, the results of which were almost identical. However, in the group of women with USI, this subjective cure rate increased to $86 \%$, which compares favourably with subjective and objective success rates reported in recent studies assessing TOT [7-13]. Deval et al. [10], in a study of 129 women who underwent Obtape, described a subjective cure rate of $77.5 \%$ and objective cure rate of $90 \%$ following an 18-month follow-up, and similar findings were recently reported by Darai et al. [11], who

Table 5 Comparisons of sexual life for sexually active women before and after transobturator tension-free vaginal tape (TOT)

objective and subjective evaluation of the surgical outcome has been the subject of endless debate. Despite its poor correlation with patient symptoms [21], urodynamic evaluation is considered the gold standard, as it differentiates between true failures, i.e. persistent USI, and those with DO. However, urodynamics may be impractical in postoperative assessment, as it subjects a large cohort of women to an invasive and costly investigation. Other noninvasive tests such as pad tests were used extensively in urogynaecology research; however, we have previously shown that the self-subjective assessment of UI strongly correlated with the result of the standard 1-h pad test [22].

This is a retrospective study and therefore subject to the potential flaw of recall bias, especially with the long period of follow-up (10-40 month); on the other hand, it may give a true reflection of the routine clinical setting without the supportive network frequently associated with prospective trials. Nine consultants and their trainees of varying

\begin{tabular}{lrll}
\hline & Baseline $(n)$ & After TOT & $P$ value \\
\hline Frequency of intercourse $(n=130)$ & & \\
$2 \pm$ week & $20(15.4 \%)$ & $20(15.4 \%)$ & 1.0000 \\
$1-2 /$ week & $48(36.9 \%)$ & $57(43.8 \%)$ & 0.1637 \\
$1-3 /$ month & $42(32.3 \%)$ & $28(21.5 \%)$ & $0.0108^{*}$ \\
Less & $20(15.4 \%)$ & $25(19.3 \%)$ & 0.4049 \\
Penetration $(n=130)$ & & & \\
Enjoyable & $85(65.4 \%)$ & $83(63.8 \%)$ & 0.8551 \\
Painful & $21(16.2 \%)$ & $25(19.2 \%)$ & 0.5708 \\
Neither & $24(18.4 \%)$ & $22(17.0 \%)$ & 0.8388 \\
Coital Incontinence $(n=130)$ & & \\
All of the time & $14(10.8 \%)$ & $6(4.6 \%)$ & $0.0078^{*}$ \\
Most of the time & $29(22.3 \%)$ & $0(0.0 \%)$ & $<0.0001^{*}$ \\
Occasionally & $46(35.4 \%)$ & $26(20 \%)$ & $0.0034^{*}$ \\
Never & $41(31.5 \%)$ & $98(75.4 \%)$ & $<0.0001^{*}$ \\
\hline
\end{tabular}

$P$ is significant at 0.05

* Statistically significant difference 
found an $88.6 \%$ cure rate with the TOT following a mean follow-up of 10 months.

Traditionally, results of anti-incontinence surgery were considered poor in women with mixed incontinence due to possible aggravation of their overactive bladder symptoms $[23,24]$. This was recently challenged by Duckett et al. [25], who showed a $63 \%$ subjective cure of preoperative urge symptoms following TVT in women with mixed incontinence, with an interesting $47 \%$ objective cure of the preoperative DO. In our study, the subjective success rates were significantly lower in women with mixed incontinence (51\%) compared with $86 \%$ in women with USI. Preoperative urgency was not changed in the vast majority of women, whereas one third described either significant or slight improvement, and only a minority $(8.3 \%)$ described worsening of their symptom.

Intraoperative complication rates were comparable in both groups; however, more lateral vaginal wall tears occurred in the outside-in technique, reflecting the need for more surgical dissection in this group. No bladder or urethral injuries occurred with the inside-out technique, which reinforced the findings from the original study by De Leval [6]. In the Obtape group, both cases of urethral injury occurred at the time of suburethral dissection and therefore were unrelated to insertion technique and were mainly due to the thin and fibrosed vaginal wall secondary to previous repeated vaginal surgery in both cases. A single case of bladder perforation occurred and could be related to insertion technique, i.e. outside-in, and could have been detected if routine cystoscopy was used or if extra vigilance was given to the postoperative haematuria. There are case reports of bladder injury after TOT procedures [26, 27], and recently, Roumeguere et al. [9] reported three urethral $(2.5 \%)$ and one bladder $(0.8 \%)$ injury in their series of 120 women who underwent a TOT outside-in procedure. However, the majority of the literature supports insertion of a TOT, both outside-in and inside-out techniques, without the need of cystoscopy. Dargent et al. [28] and Spinosa et al. [29] reported on 71 and 117 cases of TOT, respectively, using the outside-in technique; they performed cystoscopy in all cases, and there were no cases of lower urinary tract injuries. Deval et al. [10] confirmed the same findings in their prospective series of 129 women who underwent outside-in TOT, and Bonnet et al. [30] reemphasised that cystoscopy was not needed in their recent study on cadavers using the inside-out TVT-O.

The vast majority of the potentially serious complications occurred in the Obtape group. However, comparing complications in both the Obtape and the TVT-O groups, only the late onset complications showed statistically significant difference. This can be explained by the relatively smaller number of patients in the TVT-O group. It is important to note that these complications are related to the tape material and not to the technique of insertion. An alarmingly high rate of vaginal erosions (6.6\%) and ischiorectal fosse abscesses $(1.1 \%)$ occurred in the Obtape group. These findings were comparable with those of Deval et al. [10] (6.2\% and 1.5\%, respectively); however, they were significantly lower than other reports of $13.8-20 \%$ [31 and 32, respectively] vaginal erosion rates following Obtape. The accumulating evidence of the high rates of vaginal erosion and potentially serious infection in the obturator and ischiorectal spaces following the insertion of Obtape has led to the withdrawal of this tape from the market.

Subject female sexual dysfunction has recently gained attention in the field of urogynaecology and is increasingly being considered an important outcome in postoperative patient assessment. UI during sexual intercourse, otherwise called CI, is a common symptom in patients with USI [33, 34]. In a systematic review of all the peer-reviewed publications reporting on CI, Shaw et al. [34] have shown huge variation in its prevalence $(0.6-64 \%)$, primarily due to the huge methodological heterogeneity in these studies. Ghezzi et al. [35] prospectively assessed the impact of TVT for treating USI on patients' sexual function. Although the objective cure rate of USI and CI was $98 \%$ and $87 \%$, respectively, the majority of women $(62 \%)$ reported "no change" in sexual function and 34\% reported "an improvement" compared with $3.8 \%$ who reported deterioration in their sexual life. However, the above study was limited by small population size (53 patients) and limited follow-up period (6 month). Conversely, other small series have shown deterioration of sexual function following TVT ranging from $3-20 \%[16,36,37]$. This is the first study to assess a relatively longer-term impact of TOT on patients' sexual life. CI was completely cured in $75 \%$ of patients, with another $20 \%$ reporting only occasional CI, giving an impressive rate of treatment of this particular symptom. However, this improvement in CI was not associated with a significant improvement in other factors, such as frequency of intercourse or improved pleasure during penetration. Overall, half of the women in this study reported no change in their sexual life compared with $34.5 \%$ who reported an overall improvement and 13\% reporting deterioration. The reasons for deterioration were equally divided between anxiety, dyspareunia, reduced vaginal sensation, vaginal erosions and partner-related discomfort.

\section{Conclusions}

The TOT procedure is relatively safe in the treatment of USI and is associated with a high subjective success rate with a median follow-up of 28 months. CI is likely to be cured, and the vast majority of women described improvement or no change in their sexual life following the 
procedure. There was no significant difference in complication rates between the outside-in and the inside-out techniques; however, significantly more tape-related complications occurred in the Obtape group.

\section{References}

1. Ulmsten U, Henriksson L, Johnson P et al (1996) Ambulatory surgical procedure under local anaesthetic for the treatment of female urinary incontinence. Int Urogynecol J 7:81-86

2. Petros P, Ulmsten U (1993) An integral theory and its method for the diagnosis and management of female urinary incontinence. Scand J Urol Nephrol 153:1-93

3. Ulmsten U, Falconer C, Johnson P, Jomaa M, Lanner L, Nilsson CG, Olsson I (1999) A Multicenter Study of Tension-Free Vaginal Tape (TVT) for surgical treatment of stress urinary incontinence. J Urol 162(3):971-972

4. Ward K, Hilton P (2004) A prospective multicenter randomized trial of tension-free vaginal tape and colposuspension for primary urodynamic stress incontinence: two-year follow-up. Am J Obstet Gynecol 190:324-331

5. Delorme E (2001) Transobturator urethral suspension: miniinvasive procedure in the treatment of stress urinary incontinence in women. Prog Urol 11(6):1306-1313

6. de Leval J (2003) Novel surgical technique for the treatment of female stress urinary incontinence: transobturator vaginal tape inside-out. Eur Urol 44:724-730

7. Delorme E, Droupy S, de Tayrac R, Delmas V (2004) Transobturator tape (Uratape): a new minimally-invasive procedure to treat female urinary incontinence. Eur Urol 45:203-207

8. Deval B, Ramsay I (2005) Transobturator tape: a new method in the treatment of female stress urinary incontinence. Obstet Gynaecol 7(3):192-194

9. Roumeguere T, Quackels T, Bollens R, de Groote A, Zlotta A, Vanden Bossche M, Schulman C (2005) Transobturator vaginal tape for female stress incontinence: one year follow up in 120 women. Eur Urol 48:805-809

10. Deval B, Ferchaux J, Berry R, Gambino S, Ciofu C, Rafi A, Habb F (2006) Objective and subjective cure rates after transobturator tape $\left(\right.$ Obtape $\left.{ }^{\mathbb{R}}\right)$ treatment of female urinary incontinence. Eur Urol 49(2):373-377

11. Darai E, Frobert JL, Grisard-Anaf M, Lienhart J, Fernandez H, Dubernard G, David-Montefiore E (2007) Functional results after the suburethral sling procedure for urinary stress incontinence: a prospective randomized multicentre study comparing the retropubic and transobturator routes. Eur Urol 51(3):795-801

12. Fischer A, Fink T, Zachmann S, Eickenbusch U (2005) Comparison of retropubic and outside-in transoburator sling systems for the cure of female genuine stress urinary incontinence. Eur Urol 48(5):799-804

13. David-Montefiore E, Frobert J, Frisard-Anaf M, Lienhart J, Bonnet K, Poncelet C, Darai E (2006) Peri-operative complications and pain after the suburethral sling procedure for urinary stress incontinence: a French prospective randomised multi-centre study comparing the retropubic and Transobturator route. Eur Urol 49:133-138

14. Hiller L, Bradshaw HD, Radley SC, Radley S (2002) A scoring system for the assessment of bowel and lower urinary tract symptoms in women. Br J Obstet Gynaecol 109:424-430

15. Avery K, Donovan J, Peters TJ, Shaw C, Gotoh M, Abrams P (2004) ICIQ: a brief and robust measure for evaluating the symptoms and impact of urinary incontinence. Neurourol Urodyn 23:322-330

16. Elzevier HW, Venema PL, Lycklama à Nijeholt AAB (2004) Sexual function after tension free vaginal tape (TVT) for stress incontinence: results of a mailed questionnaire. Int Urogynecol J $15: 313-318$

17. Abdel-fattah M, Ramsay I, Pringle S (2006) Lower urinary tract injuries associated with transobturator tension free vaginal tape procedure: a large retrospective study. BJOG 113(12):1377-1382

18. Abdel-fattah M, Sivanesan K, Ramsay I, Pringle S, Bjornsson S (2006) How common are tape erosions? A comparison of two versions of the transobturator tension free vaginal tape procedure. BJU 98:594-598

19. Sivanesan K, Abdel Fattah M, Tierney J (2006) Perineal cellulitis and persistent vaginal erosion following Transobturator Tape $\left(\right.$ Obtape $\left.^{\mathbb{R}}\right)$ - $\mathrm{A}$ case report and review of the literature. Int $\mathrm{J}$ Urognecol 18(2):219-221

20. Hilton P (2002) Trials of surgery for stress incontinence-thoughts on the "Humpty Dumpty principle". BJOG 109:1081-1088

21. Jarvis GJ, Hall S, Stamp S et al (1980) An assessment of urodynamic examination in incontinent women. Br J Obstet Gynaecol 87:893-896

22. Abdel-fattah M, Barrington J, Youssef M (2004) The standard 1hour pad test: does it have any value in clinical practice? Eur Urol 46(3):377-380

23. Karram MM, Bhatia NN (1989) Management of co-existent stress and urge incontinence. Br J Urol 57:641-646

24. Cardozo L (1999) Urinary incontinence. In: Edmonds K (ed) Dewhurst's text book of obstetrics and gynaecology for postgraduates, 6th edn. Blackwell Science, pp 474-504

25. Duckett J, Tamilselvi A (2006) Effect of tension free vaginal tape in women with a urodynamic diagnosis of idiopathic detrusor overactivity and stress incontinence. BJOG 113:30-33

26. Minaglia S, Ozel B, Klutke C, Ballard C, Klutke J (2004) Bladder injury during Transobturator sling. Urology 64(2):37-47

27. Smith PP, Appell RA (2006) Transobturator tape, bladder perforation, and paravaginal defect: a case report. Int J Urogynaecol 26:1-3

28. Dargent D, Bretones S, George P, Mellier G (2002) Insertion of a sub-urethral sling through the obturating membrane for treatment of female urinary incontinence. Gynecol Obstet Fertil 30:576-582

29. Spinosa JP, Dubuis PY (2005) Suburethral sling inserted by the Transobturator route in the treatment of female stress urinary incontinence: preliminary results in 117 cases. Eur J Obstet Gynaecol 123(2):212-217

30. Bonnet P, Waltregny D, Reul O, de Leval J (2005) Transobturator vaginal tape inside out for the surgical treatment of female stress urinary incontinence: anatomical considerations. J Urol 173 (4): $1223-1228$

31. Siegel AL (2005) Vaginal mesh extrusion associated with the use of mentor transobturator sling. Urology 66(5):995-999

32. Domingo S, Alama P, Ruiz N et al (2005) Diagnosis, management and prognosis of vaginal erosion after transobturator suburethral tape procedure using a non-woven thermally bonded polypropylene mesh. J Urol 173:1627-1630

33. Hilton P (1998) Urinary incontinence during sexual intercourse; a common, but rarely volunteered, symptom. Br J Obstet Gynaecol 95:377-381

34. Shaw C (2002) A systematic review of the literature on the prevalence of sexual impairment in women with urinary incontinence and the prevalence of urinary leakage during sexual intercourse. Eur Urol 42:432-440

35. Ghezzi F, Serati M, Cromi A, Uccella S, Triacca P, Bolis P (2005) Impact of tension free vaginal tape on sexual function: results of a prospective study. Int Urogynecol J 17:54-59

36. Yeni E, Unal D, Verti A, Kafali H, Ciftci H, Gulum M (2003) The effect of tension free vaginal tape (TVT) procedure on sexual function in women with stress urinary incontinence. Int Urogynecol J 14:390-394

37. Glavind K, Tetsche MS (2004) Sexual function in women before and after suburethral sling operation for stress urinary incontinence: a retrospective questionnaire study. Acta Obstet Gynecol Scand 83:965-968 